\title{
Effect of Mesh Size on Soil-Structure Interaction in Finite Element Analysis
}

\author{
Nasasira Derrick ${ }^{1}$ \\ Department of Civil and Environmental Engineering, \\ Delhi Technological University, \\ New Delhi, India.
}

\author{
Amit Kumar Srivastava ${ }^{2}$ \\ Department of Civil and Environmental Engineering, \\ Delhi Technological University, \\ New Delhi, India.
}

\begin{abstract}
Numerous consitutive models have been developed over the past years for modelling the stress-strain behaviour of soils, using finite element and/or finite difference calculations of soil structures and soil/structure interaction problems under axisymetric, plane strain, and/or general three dimensional conditions. Selection of the appropriate parameters and soil model can have a significant impact on the results of numerical analysis. In this study, the interaction of soil and reinforced cement concrete raft foundation in a sandy soil at a depth of $9 \mathrm{~m}$ below the existing ground level is analysed by using with both analytical and finite element analysis (FEM). Analytical calculations were done using method available in literature and a finite element analysis was carried out using the hardening soil model available in PLAXIS 2D (2020, connect version). The results obtained from analytical calculations were compared with those obtained from the Hardening Soil (HS) Model. In the model sizes of mesh were changed and there effect on interaction behaviour is observed by studying the strength and deformation results obtained from FEM analysis. It was observed that very fine mesh size gave more accurate results compared to the other sizes.
\end{abstract}

Keywords- Plaxis, sand, settlement, Raft

\section{INTRODUCTION}

Evaluation of correct strength and deformation behaviour of raft resting on the soil is important for safe and economical design. Strength and deformation behaviour of raft foundation can be analysed by different numerical methods. With the development of numerical methods such as finite element anaylsis and finite difference method, it has become feasible to analyse and predict the behaviour of complex soil structures and soil/structure interaction problems. Such anaylses depend on the representation of the relations between stresses and strains in a given material and are represented by a consitutive model, consisiting of mathematical expressions that model the behaviour of soil in a single element. Therefore the purpose of a consitutive model is to simulate the soil behaviour with sufficient accuracy under all conditions with sufficient accuracy under all loading conditions in the numerical computations.

\section{LITERATURE REVIEW}

The Hardening Soil model was established in 1999 [1]. In the framework of the theory of elasticity. The model involves friction hardening to model the plastic shear strain in deviatoric loading, and cap hardening to model the plastic volumetric strain in primary compression.because of these two types of hardening, the model is accurate for problems (like excavations) involving a reduction of mean effective stress and at the same time mobilization of shear strength. The verification and formulation of this model was discussed [1]. It is an advanced and latest model for the simulation and modelling of soil behaviour. The Hardening soil model requires the input of 10 parameters, i.e. three reference stifness parameters $\left(\mathrm{E}_{50}{ }^{\text {ref }}\right.$ for triaxial compression, $\mathrm{E}_{\mathrm{ur}}{ }^{\text {ref }}$ for triaxial unloading and $\mathrm{E}_{\text {oed }}{ }^{\text {ref }}$ for oedometer loading) at a reference stress level $P^{\text {ref }}$, a power, $m$, for the stress dependent stifness formulation, poisson's ratio for unloading and reloading, $\mu_{\mathrm{ur}}$, the mohr coulomb strength parameters, $\varnothing$, and $c$, the dilatancy angle, $\psi$, the $K_{o}$ value in primary one-dimensional compression $\left(\mathrm{K}_{0}{ }^{\mathrm{nc}}\right)$, a parameter called the failure ratio, $\mathrm{R}_{\mathrm{f}}$ which determines the strain level at failure [2]. Fig. 1 shows the failure criterion of the harening soil model in principal stress space. The yield surface of the hardening soil model is not fixed in principal stress space, but it can expand due to plastic straining. The Plaxis hardening model can be used to accurately predict displacement and failure for general types of soils in various geotechnical applications [3]. The model does not include anisotropic strength or stiffness, nor time-dependent behaviour (creep). The hardening soil model is also known for stress-dependency of stiffness moduli [4]. This explains that all stiffnesses increases with the pressure.

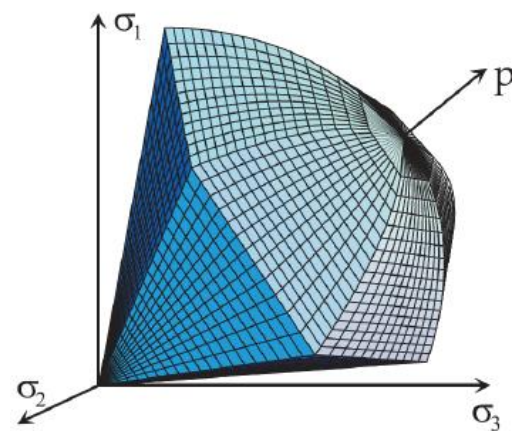

Figure 1: Failure criterion of the Hardening soil model in principal stress space [1].

The Hardening Soil model, also called as HS-Standard was explained by [1]. In order to modify the important phenomena which is exhibited by soils such as:

1. Densification, defines as decrease of the voids volume in soil due to plastic deformations, which also decreases the void ratio, 
2. Stress dependent stiffness, is basically an observed technique of increasing the stiffness modules with the increasing of confining stress,

3. Soil stress history, explains the accounting for preconsolidation process and its effects,

4. Plastic yielding, is very important which accounts for the development of irreversible strains with reaching a yield criteria,

5. Dilatancy, explains as the uses for an occurrence of negative volumetric strains during shearing.

This model is known to be one of the simplest and important in the class of latest models designed to handle the small strain stiffness as explained by [5]. It has two plastic mechanisms, shear and volumetric. Different to the other material models such as the Cap model or the Modified Cam Clay model, the magnitude of soil deformations, stresses, forces, etc. can be modelled more accurately by using three different input stiffness parameters which is related to triaxial loading stiffness $\left(\mathrm{E}_{50}\right)$, triaxial unloading-reloading stiffness $\left(\mathrm{E}_{\mathrm{ur}}\right)$, and oedometer loading modulus ( $\left.\mathrm{E}_{\mathrm{oed}}\right)$.

There are five parameters in the hardening soil model differ than the MC model is:

1. (E E $_{5 \text { ref }}$ ) secant modulus $50 \%$ strength $\left[\mathrm{kN} / \mathrm{m}^{2}\right]$

2. ( $\left.\mathrm{E}_{\text {oedref }}\right)$ Oedometric modulus $\left[\mathrm{kN} / \mathrm{m}^{2}\right]$

3. ( $\left.\mathrm{E}_{\text {urref }}\right)$ Unloading-reloading modulu $\left[\mathrm{kN} / \mathrm{m}^{2}\right]$

4. ( $\left(v_{u r}\right)$ Unloading-reloading Poisson's ratio [-]

5. (m) Exponent of the stress-stiffness function

Parameters previously used in MC model:
1. (Ø) Friction angle $\left[{ }^{\circ}\right]$
2. (c) Cohesion $\left[\mathrm{kN} / \mathrm{m}^{2}\right]$
3. $(\psi)$ Dilatancy angle $\left[{ }^{\circ}\right]$

The hardening model can be used to predict displacement and failure for different types of soils in various geotechnical applications. This model does not include anisotrpic strength or stifness, nor time-dependent behaviour (creep). It's capabilities for dynamic applications are limited, but this model is, in principle, without any doubt the most accurate general soil model.

\section{A. Correlation between Angle of Friction and Standard Penetration Number}

The peak friction angle $\varnothing$ ', of granular soil has also been correlated with $\mathrm{N}_{60}$ by several investigators. A correlation between $\mathrm{N}_{60}$ and $\varnothing$ ' was given by [6] in a graphical form, which can be approximated as,

$\emptyset^{\prime}(\mathrm{deg})=27.1+0.3 N_{60}-0.00054\left[N_{60}\right]^{2}$

B. Correlation between Modulus of Elasticity and Standard Penetration Number

The modulus of elasticity of granular soils $\left(E_{s}\right)$ is an important parameter in estimating the

elastic settlement of foundations. A first order estimation for $\mathrm{E}_{\mathrm{s}}$ was given by [7] as

$$
\frac{E_{S}}{p_{a}}=\propto N_{60}
$$

Where

$\alpha=5$ for sands with fines

10 for clean normally consolidated sands

15 for clean overconsolidated sands

$\mathrm{p}_{\mathrm{a}}=$ atmospheric pressure in the same units as $\mathrm{E}_{\mathrm{s}}$

$\mathrm{N}_{60}=$ Field standard penetration number

\section{PROBLEM STATEMENT}

Bearing capacity requirement is a basic criteria to be satisfied in the analysis and design of shallow foundations. The criterion on bearing capacity ensures that the foundation does not undergo shear failure under loading. The use of standard penetration test in the analysis of bearing capacity has received numerous attentions [8]. Details of the field application of Standard Penetration Test are specified in IS 2131 [9]. This paper attempts to report interaction behavior of raft foundations resting on sand using Finite element software package provided by Plaxis 2D (connect editon). Steps for modeling is presented in fig. 2 from the model definition to the output results

\section{SELECTION OF PARAMETERS}

Parameters used in this study were obtained through laboratory investigation of the undisturbed samples collected from site located at Noida in India, as most of the strata is having poorly graded sand, collection of undisturbed sample was difficult. Hence, the result of standard penetration test conducted as per IS 2131 [9] is used for analysis . Table 1 summarizes the selection of model paramters for analysis of the hardening soil model used in this study.

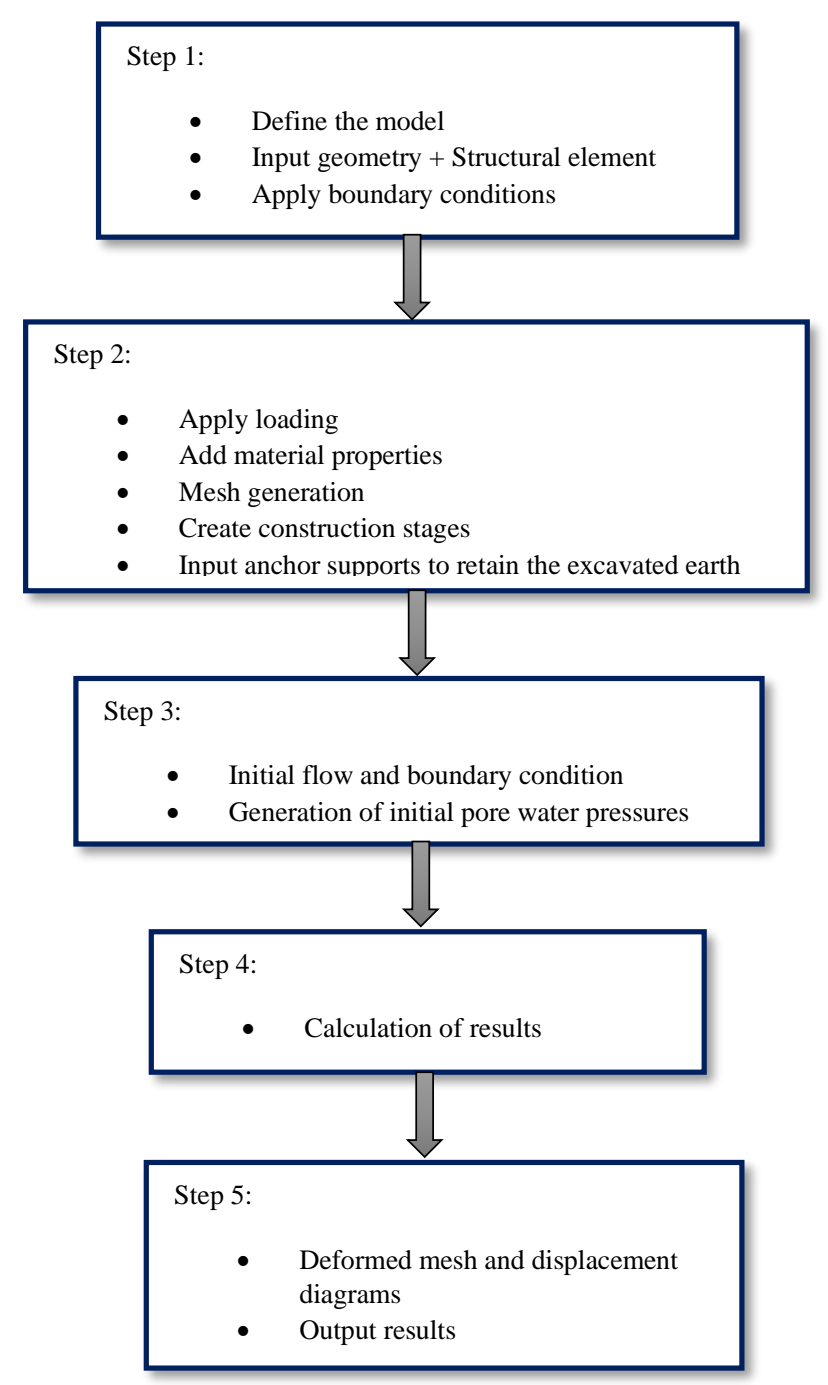

Figure 2: Steps for numerical modeling 


\section{SOIL PROFILE AND BOREHOLE DETAILS}

The samples were collected from two bore holes drilled at GH-01A/01, SECTOR-16, GREATER NOIDA WEST, U.P (India) and tested as per the relevant protocol of bureau of Indian Standard. The results of SPT are presented in Table2.

\section{ANALYTICAL METHOD}

The analytical calculations were done in accordance with Indian standards IS 6403 [10] and permissible settlement is restricted as per IS 1904 [11].

Based on the shear criterion IS code 6403 [10], net ultimate bearing capacity for local shear failure for a cohesionless sand

$$
q_{n u}=q\left(N_{q}-1\right) s_{q} d_{q} i_{q}+
$$

Where $\mathrm{s}_{\mathrm{q}}, \mathrm{s}_{\gamma}=$ shape factors

$$
\begin{aligned}
& \mathrm{d}_{\mathrm{q}}, \mathrm{d}_{\gamma}=\text { depth factors } \\
& \mathrm{i}_{\mathrm{q}}, \mathrm{i}_{\gamma}=\text { Inclination factors }
\end{aligned}
$$

$$
\begin{aligned}
& \mathrm{N}_{\mathrm{q}}, \mathrm{N}_{\gamma}=\text { Bearing capacity factors } \\
& \mathrm{w}^{\prime}, w^{\prime \prime}=\text { Correction factor for location of water }
\end{aligned}
$$
table.

Assuming there will be rise in water table during mansoon and water will reach to a level of bottom of raft.

$$
\emptyset^{\prime}=\tan ^{-1}(0.67 \tan \varnothing)=22.78^{\circ}
$$

\begin{tabular}{|c|c|c|c|}
\hline \multicolumn{4}{|l|}{ General } \\
\hline Material model & Model & Hardening soil model & - \\
\hline Type of material behaviour & Type & Drained & - \\
\hline Soil unit weight above phreatic level & $\gamma_{\text {unsat }}$ & $16.20(l a b)$ & $\mathrm{KN} / \mathrm{m}^{3}$ \\
\hline Soil unit weight below phreatic level & $\gamma_{\text {sat }}$ & $19.10(l a b)$ & $\mathrm{KN} / \mathrm{m}^{3}$ \\
\hline \multicolumn{4}{|l|}{ Parameters } \\
\hline Young's modulus & $\mathrm{E}^{\prime}$ & - & $\mathrm{KN} / \mathrm{m}^{2}$ \\
\hline Secant stiffness in standard drained triaxial test & $E_{50}$ & $3.0 \times 10^{4}$ (Plaxis) & $\mathrm{KN} / \mathrm{m}^{2}$ \\
\hline Tangent stiffness for primary oedometer loading & $E_{\text {oed }}$ & $3.0 \times 10^{4}$ (Plaxis) & $\mathrm{KN} / \mathrm{m}^{2}$ \\
\hline Unloading/reloading stiffness & $\mathrm{E}_{\mathrm{ur}}$ & $1.00 \times 10^{5}$ (Plaxis) & $\mathrm{KN} / \mathrm{m}^{2}$ \\
\hline Power for stress-level dependency of stiffness & $\mathrm{m}$ & 0.5 (Plaxis) & - \\
\hline Cohesion (constant) & $\mathrm{C}$ & $0(l a b)$ & $\mathrm{KN} / \mathrm{m}^{2}$ \\
\hline Friction angle & $\varnothing$ & $32(l a b)$ & ${ }^{\circ}$ \\
\hline Dilatancy angle & $\psi$ & $2.0(l a b)$ & o \\
\hline Poisson's ratio & $\mu$ & $0.2(l a b)$ & - \\
\hline $\mathrm{K}_{0}$-value for normal consoilidation & $\mathrm{K}_{0}^{\mathrm{nc}}$ & 0.4701 (plaxis) & - \\
\hline \multicolumn{4}{|l|}{ Interfaces } \\
\hline Strength reduction factor Inter. & $\mathrm{R}_{\text {inter }}$ & 0.67 (plaxis) & - \\
\hline \multicolumn{4}{|l|}{ Initial } \\
\hline $\mathrm{K}_{0}$ determination & - & Automatic & - \\
\hline Over-consolidation ratio & OCR & 1.0 (plaxis) & - \\
\hline
\end{tabular}

$$
\mathrm{Nq}=8.76, \mathrm{~N} \gamma=8.44
$$

$$
\begin{aligned}
& \text { from equation (3), } q_{n u}=\gamma D_{f}\left(N_{q}-1\right) s_{q} d_{q} i_{q} w^{\prime}+ \\
& \frac{1}{2} B \gamma N_{\gamma} s_{\gamma} d_{\gamma} i_{\gamma} w^{\prime \prime}=2209.88 \mathrm{KN} / \mathrm{m}^{2}
\end{aligned}
$$

Assuming a factor of safety of 2.5, net safe bearing capacity $(\mathrm{q}$ $=883.95 \mathrm{KN} / \mathrm{m}^{2}$

TABLE 1: SELECTION OF MODEL PARAMETERS FOR ANALYSIS USING THE HARDENING SOIL MODEL 
TABLE 2: SPT VALUES FOR DIFFERENT BOREHOLES

\begin{tabular}{|c|c|c|c|c|}
\hline & \multicolumn{2}{|c|}{ B1 } & \multicolumn{2}{c|}{ B2 } \\
\hline $\begin{array}{l}\text { Depth } \\
(\mathrm{m})\end{array}$ & $\begin{array}{l}\text { Field } \\
\text { N- } \\
\text { Value }\end{array}$ & $\begin{array}{l}\text { Corrected } \\
\text { N-value }\end{array}$ & $\begin{array}{l}\text { Field } \\
\text { N- } \\
\text { Value }\end{array}$ & $\begin{array}{l}\text { Corrected } \\
\text { N-value }\end{array}$ \\
\hline 1.5 & 10 & 17 & 7 & 12 \\
\hline 3 & 12 & 17 & 9 & 13 \\
\hline 4.5 & 18 & 21 & 13 & 15 \\
\hline 6 & 20 & 20 & 17 & 17 \\
\hline 7.5 & 24 & 22 & 19 & 17 \\
\hline 9 & 25 & 21 & 24 & 20 \\
\hline 10.5 & 26 & 20 & 27 & 21 \\
\hline 12 & 34 & 24 & 29 & 21 \\
\hline 13.5 & 37 & 25 & 30 & 18 \\
\hline 15 & 39 & 20 & 34 & 19 \\
\hline 18 & 44 & 21 & 39 & 20 \\
\hline 21 & 51 & 22 & 46 & 21 \\
\hline 24 & 56 & 23 & 52 & 22 \\
\hline 27 & 58 & 23 & 54 & 22 \\
\hline 30 & 59 & 23 & 59 & 23 \\
\hline 33 & 55 & 21 & 62 & 23 \\
\hline 36 & 60 & 22 & 66 & 23 \\
\hline 39 & 68 & 23 & 71 & 24 \\
\hline 42 & 70 & 23 & 76 & 25 \\
\hline 45 & 75 & 24 & 81 & 25 \\
\hline
\end{tabular}

TABLE 3: PARAMETER USED FOR CALCULATION BY ANALYTICAL METHOD

\begin{tabular}{|c|c|c|c|}
\hline Bore hole No & $1 \& 2$ & Unit & Protocol \\
\hline Depth of water table & 14 & $\mathrm{~m}$ & \\
\hline $\begin{array}{l}\text { density above water } \\
\text { table }\end{array}$ & 16.2 & $\mathrm{KN} / \mathrm{m}^{3}$ & \\
\hline $\begin{array}{l}\text { density below water } \\
\text { table }\end{array}$ & 19.1 & $\mathrm{KN} / \mathrm{m}^{3}$ & \\
\hline Type of foundation & raft & & \\
\hline width of foundation & 40 & $\mathrm{~m}$ & \\
\hline length of foundation & 42 & $\mathrm{~m}$ & \\
\hline depth of foundation & 9 & $\mathrm{~m}$ & \\
\hline $\begin{array}{l}\text { Permissible settlement } \\
\text { of foundation }\end{array}$ & 0.075 & $\mathrm{~m}$ & \\
\hline Cohesion $(\mathrm{c})$ & 0 & $\mathrm{kN} / \mathrm{m}^{2}$ & $\begin{array}{l}\text { Direct } \\
\text { Shear }\end{array}$ \\
\hline $\begin{array}{l}\text { Angle of internal } \\
\text { friction }(\varphi)\end{array}$ & 32 & Degree & Test \\
\hline
\end{tabular}

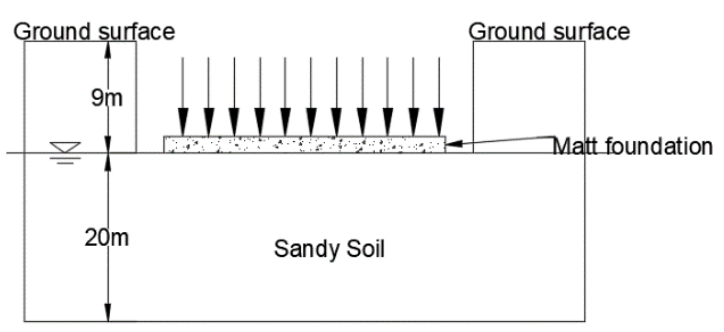

Figure 3: Prototype dimensions
Bearing capacity based on the settlement criterion

$N_{\text {cor }}=22$

$\gamma_{d}=16.2 \mathrm{KN} / \mathrm{m}^{2}$

$\gamma_{\text {sat }}=19.1 \mathrm{KN} / \mathrm{m}^{2}$

$\mu=0.2$

$C=0$

$\varnothing=32^{\circ}$

$$
S_{e}=\frac{q_{n} B\left(1-\mu^{2}\right) I_{F}}{E_{S}}
$$

Where $q_{n}=$ Net safe bearing pressure

$$
\begin{aligned}
& \mathrm{B}=\text { breadth of foundation } \\
& E_{\mathrm{S}}=\text { Young's modulus } \\
& \mathrm{I}_{\mathrm{F}}=\text { Influence factor } \\
& \mathrm{s}_{\mathrm{e}}=\text { allowable settlement }(75 \mathrm{~mm})
\end{aligned}
$$

at

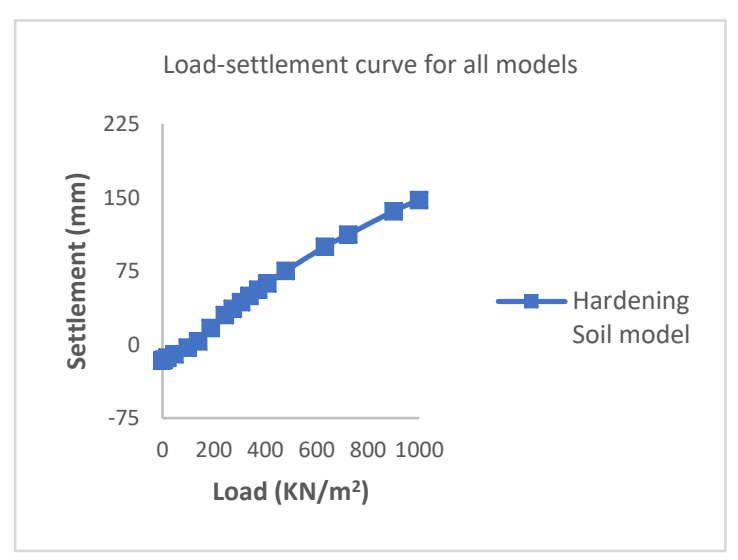

Figure 4: Load-settlement relationship for the Hardening soil model

$75 \mathrm{~mm}$ allowable settlement, from equation $4, \mathrm{q}_{\mathrm{n}}=$ $456.7 \mathrm{KN} / \mathrm{m}^{2}$. Therefore, considering the lower of the two values obtained, Allowable bearing capacity of the foundation was obtained as $456.7 \mathrm{KN} / \mathrm{m}^{2}$.

\section{NUMERICAL ANALYSIS}

Plaxis 2D was used to evaluate the performance of the Hardening Soil model model to estimate the bearing capacity of a raft foundation situated at a depth of $9 \mathrm{~m}$ below the surface and to investigate the relationship between the results obtained. Fig 3 shows a sketch of the prototype dimensions showing the location of the water table. Simulations for different excavation stages were done. The distance between the boundary of the floor of the model and the lower boundary of the footing plays an important role in the pattern of bearing capacity value obtained. 


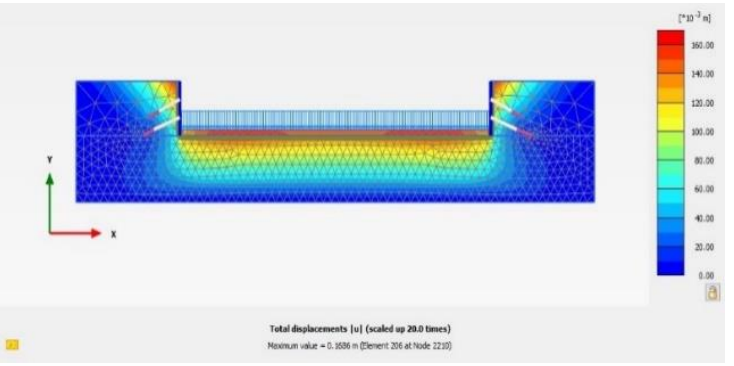

Figure 5: Output image showing total vertical displacement of foundation

To eliminate the effect of this factor, the bottom line intended at a distance greater than $2 \mathrm{~d}$.

It can be seen from fig 4, that Plaxis 2D software provides a linear load-settlement relationship for the hardening soil model, which is variant from the theoretical load-settlement curve for a foundation on sandy soil. The curve also indicates an initial negative settlement indicating a swelling in the soil before the footing is placed and load is applied. The reason for initial negative settlement is due to release of in situ soil pressure due to excavation.

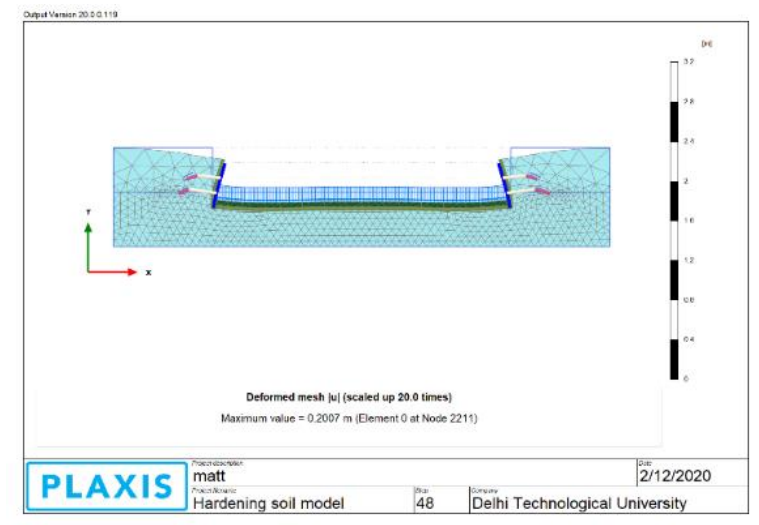

Figure 6: Deformed mesh of foundation.

It can be seen from the graph that settlement increases directly proportional to increase in stress applied on foundation. A value of $481 \mathrm{KN} / \mathrm{m}^{2}$ is obtained at $57 \mathrm{~mm}$ settlement. It can be seen that the hardening soil model provides a result close to the value obtained from the IS code calculation $\left(456.7 \mathrm{KN} / \mathrm{m}^{2}\right)$ therefore making it more accurate to use in the field for design of foundations. Fig 5 shows the deformation of the raft footing after applying the design load. The contours are drawn for different displacements value below the raft.

Fig 6 shows the typical deformed mesh of the foundation. Three excavation stages were input into Plaxis software since the foundation is laid at a $9 \mathrm{~m}$ depth. To support the dry excavation, anchors were used. The anchors were prestressed with $500 \mathrm{KN}$ force.

\section{EFFECT OF CHANGES OF MESH SIZE ON THE BEARING CAPACITY OF FOUNDATION}

Here, the effect of mesh size changes on the model output results was analysed. Different mesh sizes were used in Plaxis 2D which are; very coarse, coarse, medium, fine and very fine. It should be noted that the mesh size of 15 nodal element, is a better distribution of nodes and more accurate results than to element with six nodes. Therefore, the analysis of 15 nodal element is used. Table 3 shows the effect of changes of mesh size on settlement pressure of foundation for $75 \mathrm{~mm}$ settlement. Figure 7 shows the effect of change in mesh size on deformation of a raft foundation.

\section{TABLE 3: EFFECT OF CHANGE IN MESH SIZE ON ALLOWABLE BEARING CAPACITY OF FOUNDATION}

\begin{tabular}{|c|c|}
\hline $\begin{array}{c}\text { Allowable bearing capacity of } \\
\text { foundation at } 75 \mathrm{~mm} \\
\text { settlement }\left(\mathrm{KN} / \mathrm{m}^{2}\right)\end{array}$ & $\begin{array}{c}\text { Change in type of mesh } \\
\text { size }\end{array}$ \\
\hline 494 & Very coarse \\
\hline 488 & Coarse \\
\hline 480 & Medium \\
\hline 465 & Fine \\
\hline 460 & Very fine \\
\hline
\end{tabular}

From Fig 7, it can be seen that there is slightly or no difference in the pressure for $75 \mathrm{~mm}$ of settlement. But at settlement more than $75 \mathrm{~mm}$ the effect of mesh size is to decrease the settlement for a given pressure if mesh size is increased from very fine to very coarse.

\section{CONCLUSION}

Based on the findings, the following conclusions can be drawn;

1. The bearing pressure for a given settlement obtained by the hardening soil model was closer to the IS analytical method. However an initial settlement of $20 \mathrm{~mm}$ should be deducted to cater for the swelling provided by plaxis FEM, because of removal of insitu stress because of excavation.

2. Mesh size with 15 nodal elements produces more accurate results as compared with element with six nodes.

3. The mesh sizes influences the bearing pressure for a given settlement. The influences are negligible at a settlement

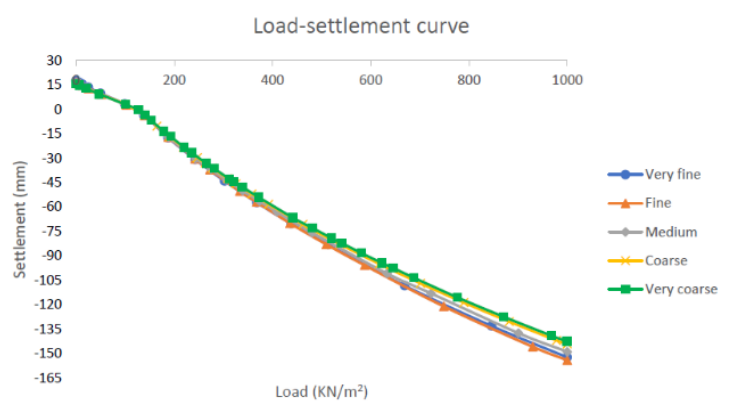

Figure 7: Load-settlement graph of the different mesh sizes

value of $75 \mathrm{~mm}$, but influences increase with increase in settlement.

4. Bearing capacity value increases with increase in refinement of mesh size in Finite element analysis. When a finer mesh is used, the value of bearing capacity obtained at a particular settlement is higher than that obtained when a coarse mesh is used. This therefore means researchers should ensure that a fine mesh is used when carrying out finite element analysis to obtain more accurate results. 


\section{ACKNOWLEDGMENT}

The authors wish to thank the Department of Civil Engineering, Delhi Technological University. This work was supported in part by a grant from delhi Technological University, Department of Civil and Environmental Engineering.

\section{REFERENCES}

[1] Schanz T, Vermeer A, Bonnier P, (1999), "The hardening soil model: formulation and verification." Beyond 2000 Computional Geotechnics-10 years PLAXIS, Amsterdam, Netherlands, 281p.

[2] Brinkgreve RBJ, Al-Khoury R, (2020), "PLAXIS version 2020 reference manual".

[3] Braja, MD. (1999), "Principle of Foundation Engineering (4th edi.)". PWE Publishing Company, USA. pp243.

[4] Labuz, Joseph \& Zang, Arno. (2015). "Mohr-coulomb failure criterion". The ISRM Suggested Methods for Rock Characterization, Testing and Monitoring: 2007-2014. 227-231.

[5] Hewitt, P. B. and Gue, S. S., (1994). "Piled Raft Foundation in a weathered sedimentary formation. Proc. Geotropica”, Malaysia, 111

[6] Peck, Hanson and Thornburn (1974), "Modification of Teraghi and Peak Correlation by Peak, Hanson and Thornburn"

[7] Kulhawy, F.H. \& Mayne, Paul, (1990). "Manual on Estimating Soil Properties for Foundation Design".

[8] Poulos, H.G., (2005). "Piled raft and compensated piled raft foundations for soft soil sites. Advances on designing and testing deep foundations". Geotech. Spec. Publ. (ASCE) 129: 214-235.

[9] Indian standards, IS:2131. (1981), "Method for standard penetration test for soils"

[10] Indian standards, IS:6403. (1981), "Code of Practice for Determination of Bearing Capacity of Shallow Foundations".

[11] Indian standards, IS:1904. (1986), "Code of practice for design and construction of foundations in soils : general requirements".

[12] Józsa, Vendel. (2011), "Effects of rarely analyzed soil parameters for FEM analysis of embedded retaining structures".

[13] Shield RT (1955)., "On Coulomb's law of failure in soils". J Mech Phys Sol 4:10-16

[14] Jerry A Yamamuro., Victor N,(2005), "Soil constitutive models, Evaluation, selection, and calibration". Geotechnical Special Publication No.128.

[15] Meyerhof, GG. (1956), "Penetration Test and Bearing Capacity of Cohesionless Soils". Journal of the Soil Mechanics and Foundation Division, ASCE. 82(1):1-19.

[16] Adachi, T., Oka, F., (1982). "Constitutive equation for normally consolidated clays based on elasto-viscoplasticity" Soils and foundations 22:57-70

[17] Broja, R.I., Kavaznjian, E, (1985). "A constitutive model for the $\sigma$ $\varepsilon$-t behaviour of wet clays". Geotechnique 35: 293-298.

[18] Russo, G., (1998). "Numerical Analysis of Piled Rafts. Int. J. Numer. Anal. Meth. Geomech", 22, 477-493.

[19] Prakoso, W. A. and Kulhawy, F. H., (2001). "Contribution To Piled Raft Foundation Design. Journal of Geotechnical and Geoenvironmental Engineering”, ASCE, 127(1), 17-24.

[20] Reul, O. and Randolph, M. F., (2003). "Piled Rafts in Overconsolidated Clay: Comparison of in situ Measurements and Numerical Analysis". Géotechnique, 53(3), 301-315. 